\title{
Synthesis of $\mathrm{SrCrO}_{4}$ nanostructures by onion inner-coat template and their optical properties
}

\author{
PING CHEN ${ }^{1,2}$, QING-SHENG WU ${ }^{1, *}$, YA-PING DING ${ }^{3}$ and PIN-SHI YUAN ${ }^{1}$ \\ ${ }^{1}$ Department of Chemistry, Tongji University, 1239 Siping Road, Shanghai 200092, P.R. China \\ ${ }^{2}$ Department of Chemistry, Chizhou College, Chizhou, Anhui 247000, P.R. China \\ ${ }^{3}$ Department of Chemistry, Shanghai University, Shanghai 200436, P.R. China
}

MS received 18 November 2007

\begin{abstract}
This paper describes a bio-template method of the squama inner coat of onion for preparing the $\mathrm{SrCrO}_{4}$ nanostructures including nanospheres, nanorods and dumbbell-shaped superstructure. The method is able to make $\mathrm{SrCrO}_{4}$ nanoparticles with average diameters in the range of 90-170 nm, $\mathrm{SrCrO}_{4}$ nanorods with length in the range 0.70-2 $\mu \mathrm{m}$, width in the range of 80-180 nm, and $\mathrm{SrCrO}_{4}$ dumbbell-shaped superstructure with length in the range 10-14 $\mu \mathrm{m}$. The dumbbell-shaped superstructures are assembled by many $\mathrm{SrCrO}_{4}$ nanowires with length in the range $10-14 \mu \mathrm{m}$ and width in the range $30-50 \mathrm{~nm}$. The products were characterized by transmission electron microscope, powder $\mathrm{X}$-ray diffraction, UV-Vis spectroscopy and luminescence spectrophotometer. A possible formation mechanism was also proposed. In the preparation, the $\mathrm{SrCrO}_{4}$ nanostructures were synthesized at room temperature without any surfactants. This new bio-template method will have potential applications in preparation of the nanoscale materials with different morphologies.
\end{abstract}

Keywords. Inorganic compounds; nanostructures; optical properties; $\mathrm{SrCrO}_{4}$; inner coat of onion.

\section{Introduction}

As is well known, nanomaterials have attracted great interest in the past decade because of their marvellous characteristics that are different from those of bulk materials (Alivisatos 1996; Nie and Emery 1997; Link and El-Sayed 1999; Guo et al 2005). One-dimensional nanoscale materials such as nanorods, nanowires and nanobelts, may have wide potential and practical applications because of their unique chemical and physical properties and have attracted wide attention ( $\mathrm{Hu}$ et al 1999; Vayssieres 2003). Strontium chromate $\left(\mathrm{SrCrO}_{4}\right)$ is of importance owing to its important optical behaviour, structural properties and potential applications. Especially, Zou et al recently developed $\mathrm{MCrO}_{4}$ $(\mathrm{M}=\mathrm{Ba}, \mathrm{Sr})$ catalyst, which may have promising application in the photocatalyst (Schenker et al 1998; Yin et al 2003). Up to now, considerable efforts have been focussed on the properties of $\mathrm{SrCrO}_{4}$. However, to the best of our knowledge, there are several reports on the synthesis of $\mathrm{SrCrO}_{4}$ nanostructures. For example, Chen et al (2006) reported the surfactant-assisted synthesis of $\mathrm{SrCrO}_{4}$ nanostructures by microemulsion-based technique. Wang et al (2006) reported the synthesis of $\mathrm{SrCrO}_{4}$ nanowires by a solutionphase method. Recently, our team has successfully prepared $\mathrm{SrCrO}_{4}$ crystals with different morphologies (Yang et al 2007).

\footnotetext{
*Author for correspondence (qswu@ $@$ mail.tongji.edu.cn)
}

Now it is very important to develop facile and green technologies in nanomaterials synthesis (Sastry et al 2003; Gericke and Pinches 2006; Mandal et al 2006; Huang et al 2007). In the past several years, there have been some reports on the synthesis of inorganic materials using biological systems (Li et al 2004; Zhang et al 2006). An onion is a traditional vegetable and is available in the supermarkets in many countries. Its squama consists of larger amounts of celluloses, proteins and many kinds of amino acids (Kopsell and Randle 1997; Luan 2002). In principle, these various functionalities such as hydroxyl, carboxylate and amine groups should offer a wide variety of nucleation sites for surface controlled inorganic deposition, and could be used in the synthesis of inorganic materials. It is very inexpensive and, though thin, a squama inner coat of onion is stable in a solution (Luan 2002). A squama inner coat of onion probably is an ideal biological template for the synthesis of inorganic materials.

In this work, we present a novel and simple route using the squama coat of onion as template for the preparation of $\mathrm{SrCrO}_{4}$ nanostructures including $\mathrm{SrCrO}_{4}$ nanospheres, nanorods and dumbbell-shaped superstructure. The products were characterized by scanning electron microscope (SEM), powder X-ray diffraction (XRD), UV-Vis spectroscopy and luminescence spectrophotometer (PL). In the synthesis, the nanomaterials were synthesized at room temperature without use of surfactants. This new biotemplate method will have potential applications in preparation of the other nanoscale materials, especially super- 
structure nanomaterials. The as-prepared $\mathrm{SrCrO}_{4}$ nanostructures may be used in optical and electronic devices.

\section{Experimental}

\subsection{Reagents and equipment}

All the reagents used were of analytical purity and used without further purification. $\mathrm{K}_{2} \mathrm{CrO}_{4}$ and $\mathrm{SrCl}_{2}$ were purchased from Shanghai Chemical Reagent Factory, China.

The scanning electron microscopic (SEM) images were acquired on a scanning electron microscope. XRD pattern of the sample was measured on a Rigaku X-ray diffraction with $\mathrm{CuK} \alpha$ radiation $(\lambda=0 \cdot 154056 \mathrm{~nm}$ (Japan)). The optical properties of the products were studied by an Agilent UV-Vis spectroscopy. PL spectra were obtained using a Perkin-Elmer LSS-55 luminescence spectrophotometer (USA).

\subsection{Synthesis}

The synthesis of $\mathrm{SrCrO}_{4}$ was simply achieved by the reaction between strontium and chromate ions. In a typical preparation (figure 1), a fresh onion was washed and the squama inner coat was separated from it. The inner coat was immersed in deionized water for $5 \mathrm{~min}$. Then it was fastened in a reactor and separated the reactor into two compartments. A solution of $\mathrm{K}_{2} \mathrm{CrO}_{4}(25 \mathrm{~mL})$ and a solution of $\mathrm{SrCl}_{2}(25 \mathrm{~mL})$ were respectively placed on both sides of the coat in a vertical direction. The system was kept at a certain temperature. Then the products appeared in the two compartments of the reactor. The solution containing products was centrifugally separated, and washed in turn with deionized water and absolute alcohol, and the final products were obtained.

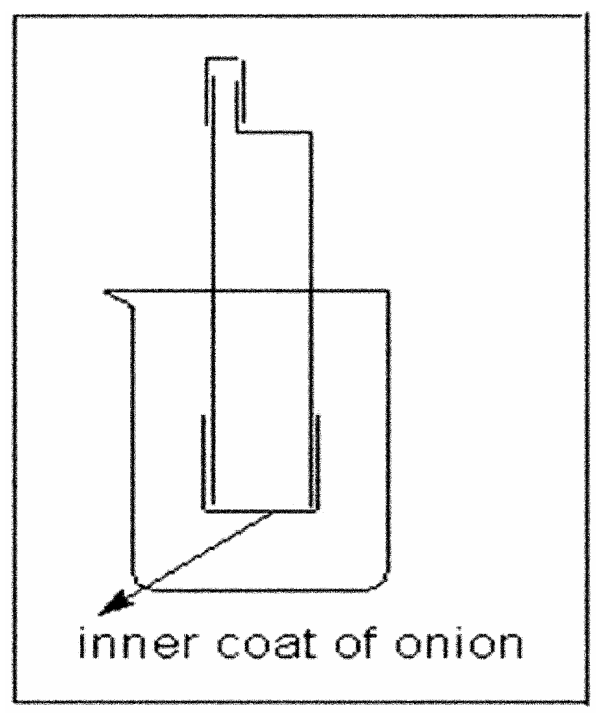

Figure 1. Scheme of the reacting cell.

\subsection{Characterization}

The morphologies of the final product were observed using SEM. The structures were characterized by XRD using a Japan Rigaku X-ray diffractometer, and the optical properties of the product were studied by fluorescence and UV-Vis spectrophotometers.

\section{Results and discussion}

\subsection{Structures and morphologies}

The overview morphologies and size of the products were observed by SEM. Figure 2 presents the SEM images. When the concentration of $\mathrm{SrCl}_{2}$ and $\mathrm{K}_{2} \mathrm{CrO}_{4}$ was both $0.1 \mathrm{~mol} / \mathrm{L}$, the SEM image of product is as shown in figure $2 \mathrm{a}$, which shows that the obtained products are of $\mathrm{SrCrO}_{4}$ nanoparticles with average diameters in the range 90-170 nm. When the concentration of $\mathrm{SrCl}_{2}$ and $\mathrm{K}_{2} \mathrm{CrO}_{4}$ was both $0.4 \mathrm{~mol} / \mathrm{L}$, the SEM image of product is as shown in figure $2 b$. Figure $2 b$ shows that the obtained products are of one-dimension $\mathrm{SrCrO}_{4}$ nanorods with length in the range $0 \cdot 70-2 \mu \mathrm{m}$ and width in the range $80-180 \mathrm{~nm}$. Figure 2c presents $\mathrm{SrCrO}_{4}$ dumbbell-shaped superstructure with length in the range 10-14 $\mu \mathrm{m}$, which was obtained when the concentration of $\mathrm{SrCl}_{2}$ and $\mathrm{K}_{2} \mathrm{CrO}_{4}$ was both $0.2 \mathrm{~mol} / \mathrm{L}$. Figure $2 \mathrm{~d}$ is the high magnification SEM image of the dumbbell-shaped superstructure. The dumbbellshaped superstructures are assembled by many $\mathrm{SrCrO}_{4}$ nanowires with length in the range $10-14 \mu \mathrm{m}$ and width in the range $30-50 \mathrm{~nm}$. All the $\mathrm{SrCrO}_{4}$ nanostructures were obtained when the reaction time was $28 \mathrm{~h}$. The asprepared $\mathrm{SrCrO}_{4}$ nanorods and dumbbell-shaped superstructure may be used in optical and electronic devices in the future. Figure 3 shows the SEM image of product when the $\mathrm{SrCl}_{2}$ and $\mathrm{K}_{2} \mathrm{CrO}_{4}$ are directly mixed together with a concentration of $0 \cdot 2 \mathrm{~mol} / \mathrm{L}$. From figure 3, irregular $\mathrm{K}_{2} \mathrm{CrO}_{4}$ rods can be seen. This indicates that the squama inner coat of onion plays a key role in the preparation of $\mathrm{SrCrO}_{4}$ nanostructures.

Figure 4 shows typical XRD patterns of the as-prepared $\mathrm{SrCrO}_{4}$ nanorods. The XRD patterns show that the $\mathrm{SrCrO}_{4}$ nanorod has a monoclinic structure (JC-PDS no. $35-0743$ ) belonging to $P 21 / n$ (14) group. The XRD patterns of the as-prepared $\mathrm{SrCrO}_{4}$ nanospheres and dumbbellshaped superstructure are similar to that of the nanorods.

\subsection{Optical properties of products}

The optical properties of nanoscale materials are the most important ones. For $\mathrm{SrCrO}_{4}$, the conduction band is composed of the $\mathrm{Cr}$ (VI) $3 d$ orbital and the valence band is composed of the O $2 p$ orbital. Because of the electronic excitation from the $\mathrm{O} 2 p$ state to the $\mathrm{Cr}$ (VI) $3 d^{0}$ state, the optical absorption produces in the region of UV-visible 

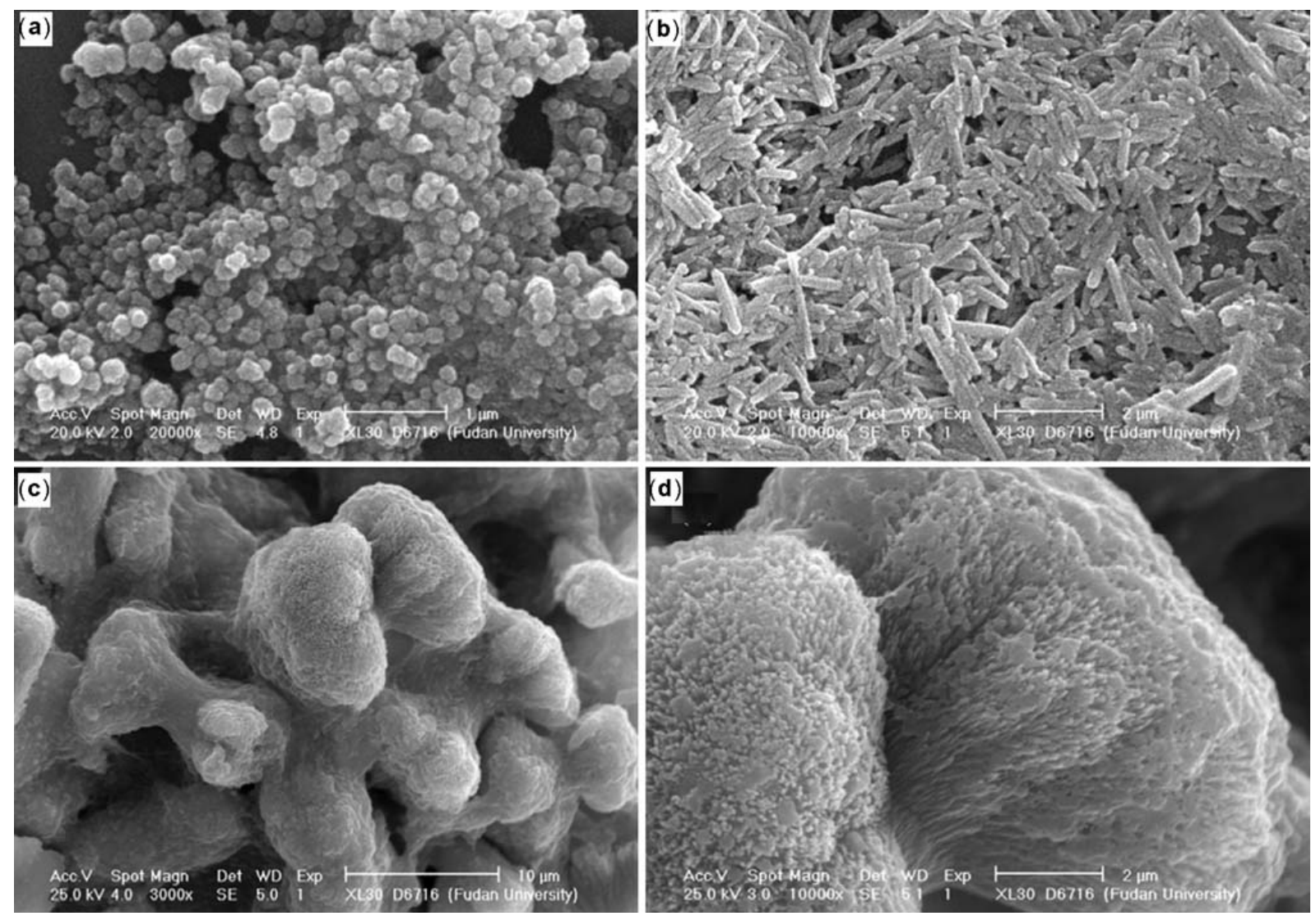

Figure 2. SEM micrographs of $\mathrm{SrCrO}_{4}$ nanospheres (a), nanorods (b), dumbbell-shaped superstructure (c) and dumbbell-shaped superstructure (magnified) (d) (a. $0.1 \mathrm{~mol} / \mathrm{L} \mathrm{K}_{2} \mathrm{CrO}_{4}, 0 \cdot 1 \mathrm{~mol} / \mathrm{L} \mathrm{SrCl}_{2}, 28 \mathrm{~h}$; b. $0.4 \mathrm{~mol} / \mathrm{L} \mathrm{K}_{2} \mathrm{CrO}_{4}, 0.4 \mathrm{~mol} / \mathrm{L}$ $\mathrm{SrCl}_{2}, 28 \mathrm{~h}$; c and d. $0.2 \mathrm{~mol} / \mathrm{L} \mathrm{K}_{2} \mathrm{CrO}_{4}, 0.2 \mathrm{~mol} / \mathrm{L} \mathrm{SrCl}_{2}, 28 \mathrm{~h}$ ).

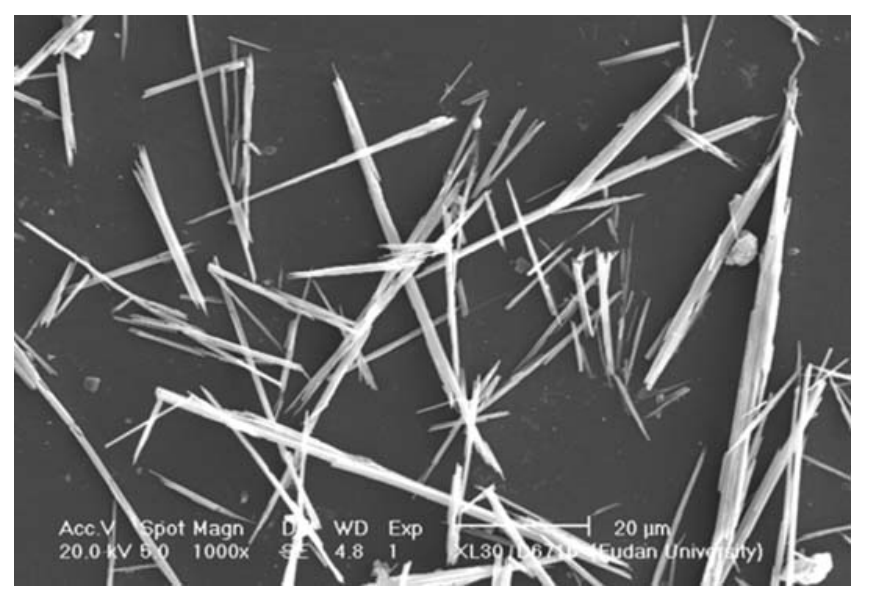

Figure 3. SEM micrographs of the products when $0.2 \mathrm{~mol} / \mathrm{L}$ $\mathrm{SrCl}_{2}$ and $0 \cdot 2 \mathrm{~mol} / \mathrm{L} \mathrm{K}_{2} \mathrm{CrO}_{4}$ are directly mixed together.

light. UV-Vis and photoluminescence properties of the as-prepared $\mathrm{SrCrO}_{4}$ nanostructures were carefully researched. UV-Vis spectra of $\mathrm{SrCrO}_{4}$ nanostructures are shown in figure 5. It can be seen that the $\mathrm{SrCrO}_{4}$ nanostructures exhibit a broad, strong optical absorption in the region of UV-visible light. In figure 5a, $\mathrm{SrCrO}_{4}$ nano- spheres showed maximum absorption peak at about $374 \mathrm{~nm}$. UV-visible absorption spectra of the $\mathrm{SrCrO}_{4}$ nanorods (figure $5 \mathrm{~b}$ ) showed maximum absorption peak at about $389 \mathrm{~nm}$. The products of $\mathrm{SrCrO}_{4}$ dumbbell-shaped superstructure have strong absorption peaks at $384 \mathrm{~nm}$ (figure 5c). Compared with the results of Yin et al (2003), the $\mathrm{SrCrO}_{4}$ nanospheres, nanorods and dumbbellshaped superstructure show obvious blue shift in UVvisible absorption. Compared with $\mathrm{SrCrO}_{4}$ nanorods and $\mathrm{SrCrO}_{4}$ dumbbell-shaped superstructure, $\mathrm{SrCrO}_{4}$ nanospheres showed blue shift at $15 \mathrm{~nm}$ and $11 \mathrm{~nm}$, respectively. Compared with $\mathrm{SrCrO}_{4}$ nanospheres, $\mathrm{SrCrO}_{4}$ nanorods show broader UV-visible absorption.

The photoluminescence properties of the $\mathrm{SrCrO}_{4}$ nanostructures are shown in figure 6 with a $220 \mathrm{~nm}$ excitation line at room temperature. Figures $6 \mathrm{a}-\mathrm{c}$ show the photoluminescence properties of the $\mathrm{SrCrO}_{4}$ nanospheres, nanorods and dumbbell-shaped superstructure. $\mathrm{SrCrO}_{4}$ nanospheres have shown a strong emission band peaking at $505 \mathrm{~nm}$ and two weak emission bands peaking at $484 \mathrm{~nm}$ and $531 \mathrm{~nm}$, respectively. $\mathrm{SrCrO}_{4}$ nanorods have shown a strong emission band peaking at $504 \mathrm{~nm}$ and two weak emission bands peaking at $486 \mathrm{~nm}$ and $530 \mathrm{~nm}$, respectively. $\mathrm{SrCrO}_{4}$ dumbbell-shaped superstructures 
have shown a strong emission band peaking at $507 \mathrm{~nm}$ and two weak emission bands peaking at $486 \mathrm{~nm}$ and $530 \mathrm{~nm}$, respectively.

\subsection{Effect of preparation parameters of $\mathrm{SrCrO}_{4}$ nanostructures}

Many experiments have been performed to explore the preparation condition of the $\mathrm{SrCrO}_{4}$ nanostructures. Results show that the reaction solution concentration and system temperature can affect the products. Experimental results show that the reaction solution concentration plays a key role in preparation (figure 2). When the concentration of $\mathrm{Sr}^{2+}$ ion and $\mathrm{CrO}_{4}^{2-}$ ion was lower, the products obtained are the $\mathrm{SrCrO}_{4}$ nanospheres. When the medium reaction

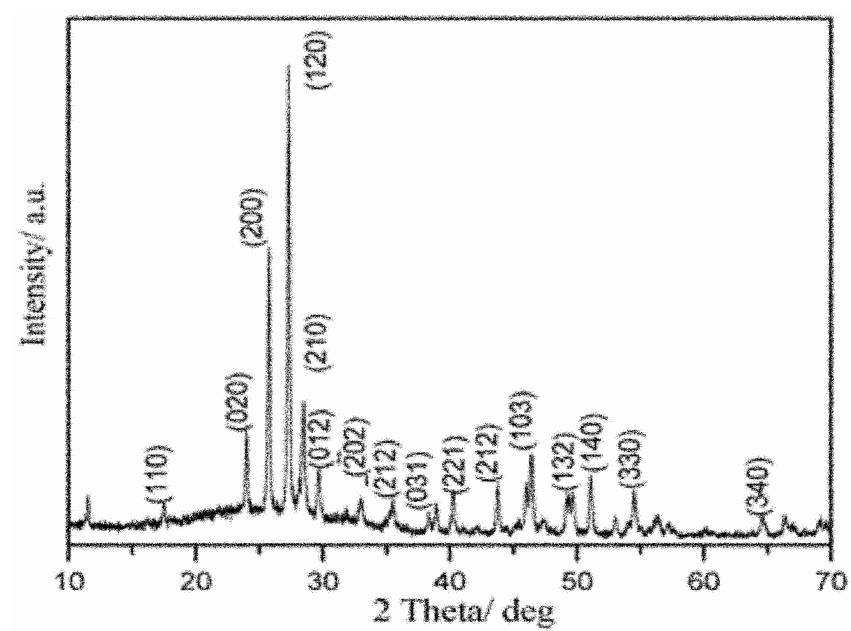

Figure 4. $\mathrm{XRD}$ patterns of $\mathrm{SrCrO}_{4}$ nanorods.

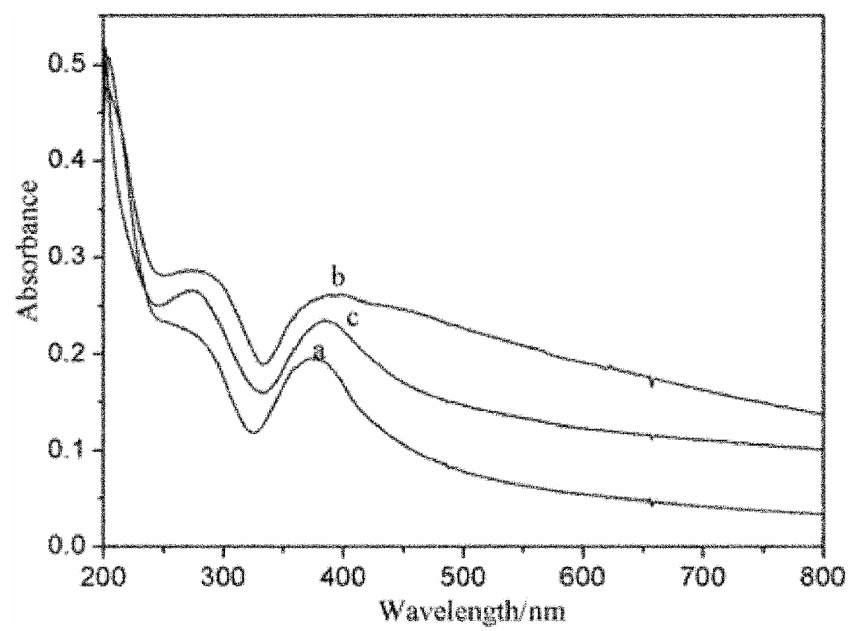

Figure 5. UV-Vis spectra of $\mathrm{SrCrO}_{4}$ nanospheres (a), nanorods (b) and dumbbell-shaped superstructure (c). (a. $0.1 \mathrm{~mol} / \mathrm{L}$ $\mathrm{K}_{2} \mathrm{CrO}_{4}, 0.1 \mathrm{~mol} / \mathrm{L} \mathrm{SrCl}_{2}, 28 \mathrm{~h} ;$ b. $0.4 \mathrm{~mol} / \mathrm{L} \mathrm{K}_{2} \mathrm{CrO}_{4}, 0.4 \mathrm{~mol} / \mathrm{L}$ $\mathrm{SrCl}_{2}, 28 \mathrm{~h}$; c. $0.2 \mathrm{~mol} / \mathrm{L} \mathrm{K}_{2} \mathrm{CrO}_{4}, 0.2 \mathrm{~mol} / \mathrm{L} \mathrm{SrCl}_{2}, 28 \mathrm{~h}$ ). solution concentration is selected, the dumbbell-shaped superstructures are obtained. But, when the concentration of $\mathrm{Sr}^{2+}$ and $\mathrm{CrO}_{4}^{2-}$ ions was higher, the $\mathrm{SrCrO}_{4}$ nanorods were obtained. By altering the reaction solution concentration, the $\mathrm{SrCrO}_{4}$ nanospheres, nanorods and dumbbellshaped superstructure can be obtained.

Effect of temperature on the $\mathrm{SrCrO}_{4}$ nanostructures also was studied. Experimental results show that when the temperature is lower than $15^{\circ} \mathrm{C}$, the products cannot be obtained in $28 \mathrm{~h}$. The reason probably is functional groups of a squama inner coat of onion can lose active ability. Figure 7 shows the SEM micrographs of $\mathrm{SrCrO}_{4}$ products when the temperature is $35^{\circ} \mathrm{C}$. The products are irregular nanospheres. When the temperature is higher than $37^{\circ} \mathrm{C}$, a squama inner coat of onion is not stable and

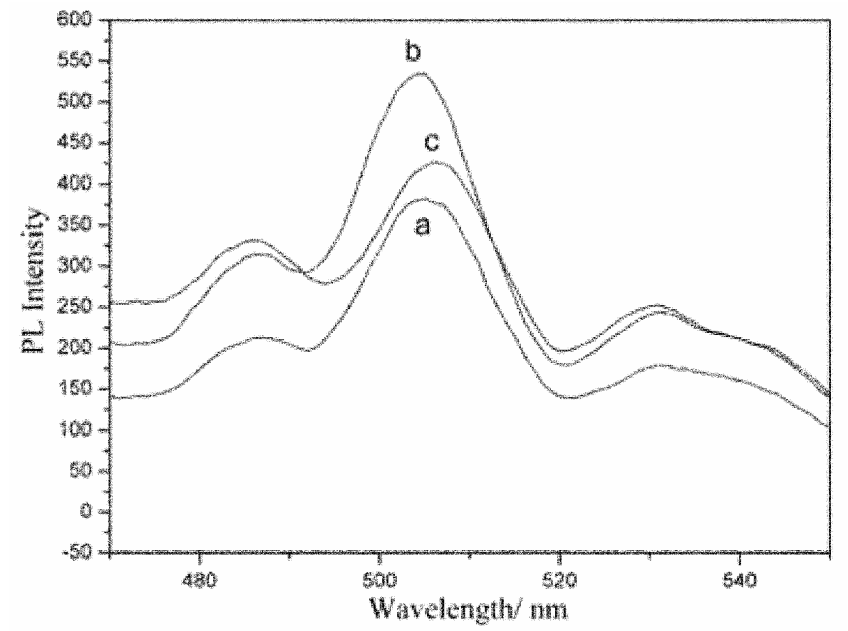

Figure 6. Fluorescent spectra of $\mathrm{SrCrO}_{4}$ nanospheres (a), nanorods (b) and dumbbell-shaped superstructure (c). (a. $0.1 \mathrm{~mol} / \mathrm{L} \mathrm{K}_{2} \mathrm{CrO}_{4}, 0.1 \mathrm{~mol} / \mathrm{L} \mathrm{SrCl}_{2}, 28 \mathrm{~h} ;$ b. $0.4 \mathrm{~mol} / \mathrm{L} \mathrm{K}_{2} \mathrm{CrO}_{4}$, $0.4 \mathrm{~mol} / \mathrm{L} \mathrm{SrCl}_{2}, 28 \mathrm{~h}$; c. $0.2 \mathrm{~mol} / \mathrm{L} \mathrm{K}_{2} \mathrm{CrO}_{4}, 0.2 \mathrm{~mol} / \mathrm{L} \mathrm{SrCl}_{2}$, $28 \mathrm{~h})$.

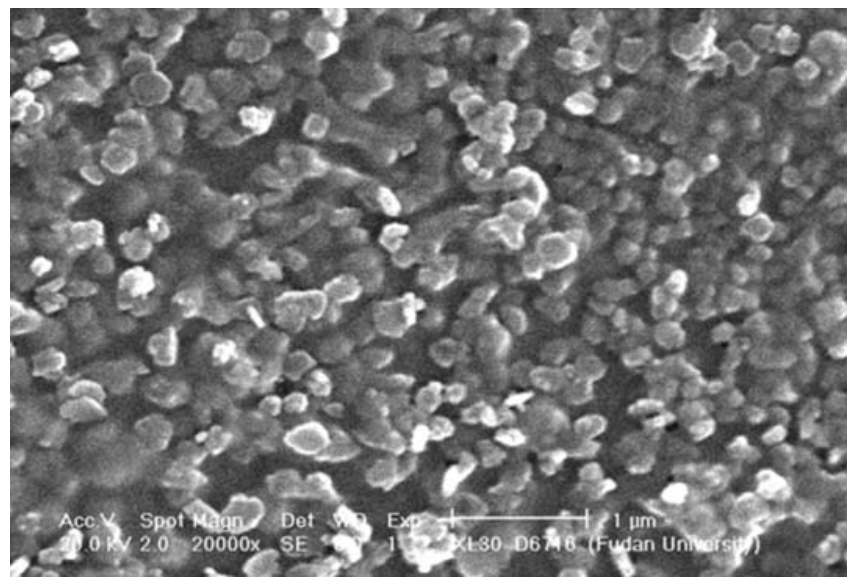

Figure 7. SEM micrographs of $\mathrm{SrCrO}_{4}$ products $(0 \cdot 1 \mathrm{~mol} / \mathrm{L}$ $\mathrm{K}_{2} \mathrm{CrO}_{4}, 0 \cdot 1 \mathrm{~mol} / \mathrm{L} \mathrm{SrCl}_{2}, 35^{\circ} \mathrm{C}$ ). 

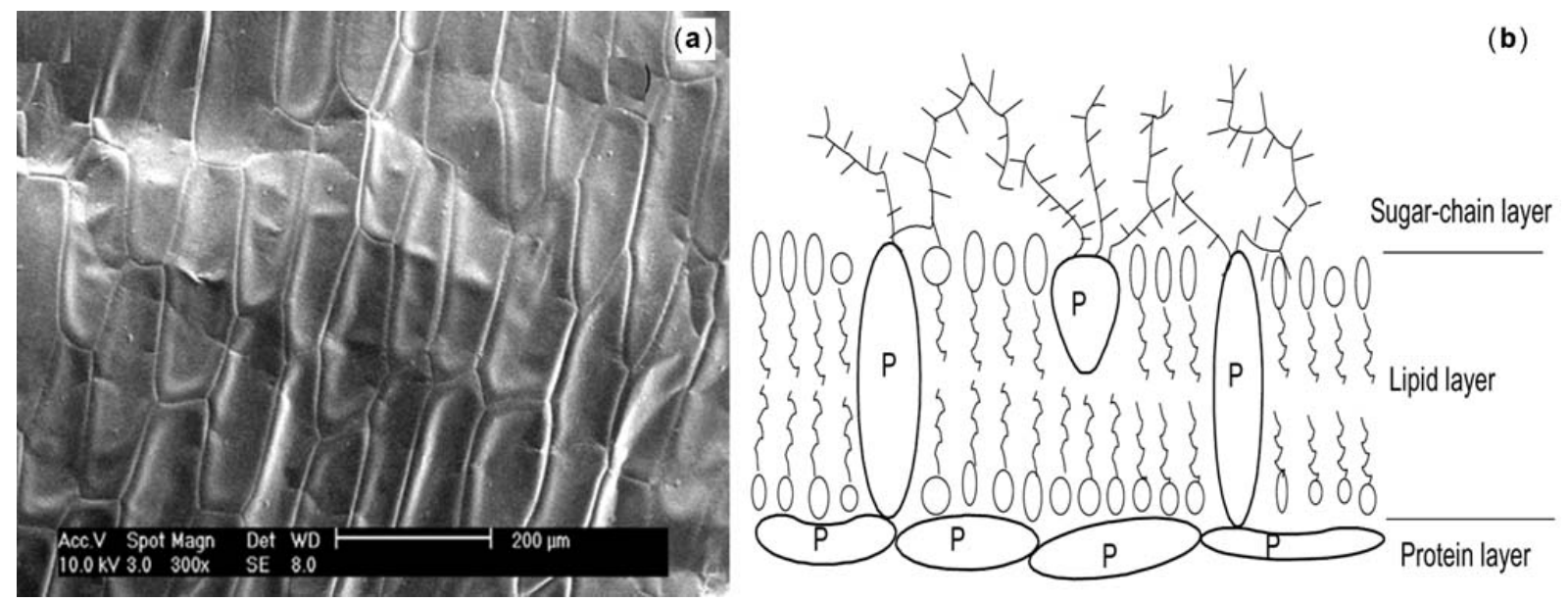

Figure 8. a. SEM micrograph of the squama inner coat of onion and $\mathbf{b}$. schematic of biological membrane (nonsymmetric trilayer model, $\mathrm{P}$ : protein).
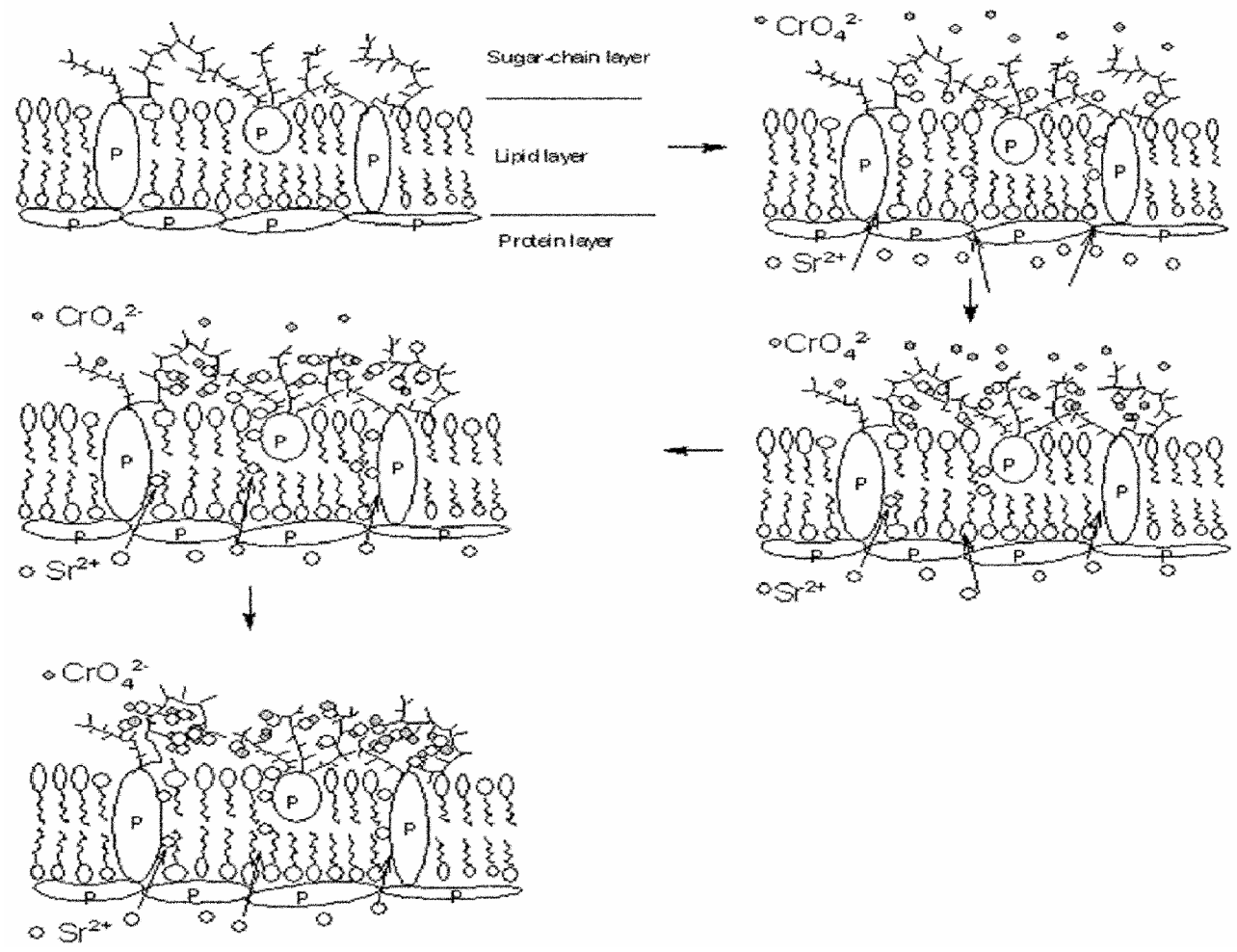

Figure 9. Schematic of the possible mechanism.

easily ruptured in a solution. In our research, $25^{\circ} \mathrm{C}$ was selected.

\subsection{Possible mechanism}

Figure 8a shows the scanning electron micrograph of the surface of squama inner coat of onion. It can be seen that the squama inner coat of onion is made up of nearly hexagonal cells, which are arranged closely. Figure 8b shows schematic of the cell membrane of the nearly hexagonal cells (non-symmetric trilayer model, $\mathrm{P}$ : protein). The bio- logical membrane mainly contains three layers: sugarchain layer, lipid layer and protein layer. The sugar-chain layer of the cell membrane and cellulose and glucoprotein system of the cell wall, which contain abundant functional groups play a key role in the formation of $\mathrm{SrCrO}_{4}$ nanostructures. The template of squama inner coat of onion includes abundant organic groups. The main groups are hydroxyl and carboxylate. These various functionalities can offer a wide variety of nucleation sites for surface controlled inorganic deposition, which could be exploited in the bio-template synthesis of inorganic materials. 


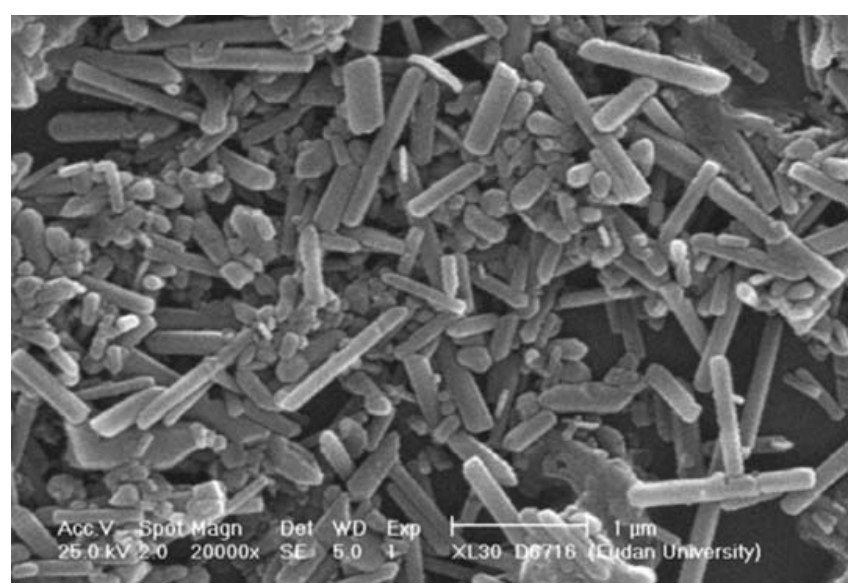

Figure 10. SEM micrograph of $\mathrm{SrCrO}_{4}$ product $(0 \cdot 2 \mathrm{~mol} / \mathrm{L}$ $\mathrm{K}_{2} \mathrm{CrO}_{4}, 0 \cdot 2 \mathrm{~mol} / \mathrm{L} \mathrm{SrCl}_{2}, 20 \mathrm{~h}$ ).

A probable mechanism for the development of the $\mathrm{SrCrO}_{4}$ nanostructures is proposed. The schematic of the development of the $\mathrm{SrCrO}_{4}$ nanospheres is shown in figure 9. First, according to the theory of hard and soft acids and bases, $\mathrm{Sr}^{2+}$ ion belongs to Lewis acid, which preferentially combine with Lewis alkaline groups, such as oxygen in the hydroxyl and carboxylate groups. Therefore, $\mathrm{Sr}^{2+}$ ions first can pass the cell membrane by permeation and combine on the wall of the squama inner coat of onion containing many hydroxyl groups mainly by electrostatic attraction. Second, when the $\mathrm{CrO}_{4}^{2-}$ ions meet $\mathrm{Sr}^{2+}$ ions, the $\mathrm{Sr}^{2+}$ ions reacted with $\mathrm{CrO}_{4}^{2-}$ ions near the surface of the squama inner coat of onion to form $\mathrm{SrCrO}_{4}$ crystal nuclei. Then the crystal nuclei were continuously produced on the interface and induced to grow into nanoparticles as time increases. Especially, during nucleation, the sugar-chain layer of the template is dominant in the nucleation positions through special confinement. The sugar-chain layer can supply an adequate site to have attractive action with $\mathrm{Sr}^{2+}$ ions and then the nanoparticles were formed.

The control of the template of squama inner coat of onion is very important in the formation of the $\mathrm{SrCrO}_{4}$ nanostructures. When the concentration of $\mathrm{Sr}^{2+}$ and $\mathrm{CrO}_{4}^{2-}$ ions was lower, on the control of the template of squama inner coat of onion, the $\mathrm{SrCrO}_{4}$ crystal nuclei could not grow in bulk unlimitedly and the growth rates in all the crystal faces were almost the same, so the $\mathrm{SrCrO}_{4}$ nanospheres can be gained. But, when the concentration of $\mathrm{Sr}^{2+}$ and $\mathrm{CrO}_{4}^{2-}$ ions was higher, on the control of the template of squama inner coat of onion, the $\mathrm{SrCrO}_{4}$ nanospheres first produce, then many nanospheres can assemble in the one-dimensional direction. Therefore, the $\mathrm{SrCrO}_{4}$ nanorods came into being. This can be supported by figure 10, which shows the SEM micrograph of $\mathrm{SrCrO}_{4}$ product when the concentration of $\mathrm{Sr}^{2+}$ ion and $\mathrm{CrO}_{4}^{2-}$ ion was both $0.4 \mathrm{~mol} / \mathrm{L}$ and reaction time was $20 \mathrm{~h}$. When the medium reaction solution concentration is selected, on the control of the template of squama inner coat of onion, the $\mathrm{SrCrO}_{4}$ little nanospheres first produce, then many of the little nanospheres can assemble in the one-dimensional direction. So, the $\mathrm{SrCrO}_{4}$ nanowires came into being. Then many $\mathrm{SrCrO}_{4}$ nanowires can self-assemble and the dumbbell-shaped superstructures are produced. Currently, it should be pointed out that the process remains highly speculative, and the detailed mechanism needs to be further investigated in future work.

\section{Conclusions}

In this paper, a simple and effective approach has been developed for the preparation of the $\mathrm{SrCrO}_{4}$ nanorods, nanospheres and dumbbell-shaped superstructure using the bio-template technique, without any surfactants. Because the method is simple, effective, mild and green, it will have potential application in synthesizing the other nanomaterials. However, in order to fully understand the mechanism for the formation of nanomaterials under the control of squama inner coat of onion, more studies will be done in the future.

\section{Acknowledgements}

The authors are grateful to the financial support of the National Natural Science Foundation of China (Nos 50772074 and 20571051) and the Nano-Foundation of Shanghai in China (No: 0652nm007).

\section{References}

Alivisatos A P 1996 Science 271933

Chen D, Tang K B, Zhang S Y, Zheng H G and Qian Y T 2006 J. Nanosci. Nanotechnol. 6738

Gericke M and Pinches A 2006 Hydrometallurgy 83132

Guo Y, Zhang H, Wang Y, Liao Z L, Li G D and Chen J S 2005 J. Phys. Chem. B109 21602

Huang J L, Li Q B and Sun D H 2007 Nanotechnology 18 105104

Hu J T, Odom T W and Lieber C M 1999 Acc. Chem. Res. 32435

Kopsell D E and Randle W M 1997 Hortscience 321260

Li L, Wu Q S and Ding Y P 2004 Nanotechnology 151877

Link S and El-Sayed M A 1999 J. Phys. Chem. B103 8410

Luan J S 2002 Shanghai Vegetables 50

Mandal D, Bolander ME, Mukhopadhyay D, Sarkar G and Mukherjee P 2006 Appl. Microbiol. \& Biotechnol. 69485

Nie S M and Emery S R 1997 Science 2751102

Sastry M, Ahmad A, Khan M I and Kumar R 2003 Curr. Sci. 85162

Schenker R P, Brunold T C and Gudel H U 1998 Inorg. Chem. 37918

Vayssieres L 2003 Adv. Mater. 15464

Wang W S, Xu C Y, Zhen L, Yang L and Shao W Z 2006 Chem. Lett. 35268

Yang X H, Wu Q S and Lju J K 2007 Cryst. Res. Technol. 42211

Yin J A, Zou Z G and Ye J H 2003 Chem. Phys. Lett. 37824

Zhang W, Zhang D, Fan T X, Ding J, Gu Q X and Ogawa H 2006 Nanotechnology 17840 